\title{
Fuzzy p-absolutely summable difference sequences
}

\begin{abstract}
Background: The significance of street food vending in providing relatively nutritious food and means of livelihoods to many people is widely acknowledged in most developing countries. However, there is a growing concern over the safety of the foods. The nature of food hygiene practice among food vendors are attributed to many factors including vendors' characteristics and operational environment, knowledge and attitude among other. This study was conducted to determine the factors associated with food hygiene practice among street food vendors in selected food vending locations of Bauchi metropolis, Nigeria. Materials and Methods: A cross-sectional study was performed on samples of 300 street food vendors operating in selected food vending locations of Bauchi metropolis, which were selected and interviewed face to face using a pretested structured questionnaire. Chi-square test was conducted to determine the food hygiene practice associated factors. Result: Out of 300 street food vendors that participated in this study, $174(58.0 \%)$ were females, averaged aged 31years, mainly characterized with low level of education 277 (92.3\%), non-attendance of food hygiene training $244(81.3 \%)$, and uncertified food businesses $246(82.0 \%)$. Majority of the respondents have good levels of knowledge regarding food hygiene 273 (91.0\%), attitudes towards food hygiene 279(93.0\%) and food hygiene practice 271(90.3) The chi-square test revealed that food hygiene training $(=4.897, \mathrm{p}=0.015)$, knowledge regarding food hygiene $(=13.541, \mathrm{p}=0.002)$ and attitude towards food hygiene $(=$ $5.172, \mathrm{p}=0.040$ ) were associated with street food vendors' food hygiene practice. Conclusions: Based on these findings, the study concluded that while street food vending in various food vending locations of Bauchi metropolis can be sustainable, food hygiene training, knowledge regarding food hygiene and attitude towards food hygiene should be prioritized and included as components of any intervention for ensuring good food practices among street food vendors.
\end{abstract}

Keyword: Food hygiene; Practice; Street foods; Vendors; Bauchi metropolis; Nigeria 
